OPEN ACCESS

Edited by:

David Gramaje,

Instituto de Ciencias de la Vid y del

Vino (ICW),

Spain

Reviewed by:

Stéphane Compant,

Austrian Institute of Technology (A/T),

Austria

Blanca B. Landa,

Spanish National Research Council (CSIC),

Spain

*Correspondence:

Philippe E. Rolshausen philrols@ucr.edu

Specialty section:

This article was submitted to Plant Microbe Interactions,

a section of the journal

Frontiers in Plant Science

Received: 21 April 2019 Accepted: 06 September 2019 Published: 04 October 2019

Citation:

Deyett E and Rolshausen PE (2019)

Temporal Dynamics of the Sap

Microbiome of Grapevine Under High

Pierce's Disease Pressure.

Front. Plant Sci. 10:1246.

doi: 10.3389/fp/s.2019.01246

\section{Temporal Dynamics of the Sap Microbiome of Grapevine Under High Pierce's Disease Pressure}

\author{
Elizabeth Deyett and Philippe E. Rolshausen* \\ Department of Botany and Plant Sciences, University of California, Riverside, CA, United States
}

Grapevine is a pillar of the California state economy and agricultural identity. This study provides a comprehensive culture-independent microbiome analysis from the sap of grapevine overtime and in a context of a vascular disease. The vascular system plays a key role by transporting nutrient, water and signals throughout the plant. The negative pressure in the xylem conduits, and low oxygen and nutrient content of its sap make it a unique and underexplored microbial environment. We hypothesized that grapevine hosts in its sap, microbes that have a beneficial impact on plant health by protecting against pathogen attack and supporting key biological processes. To address this hypothesis, we chose a vineyard under high Pierce's disease (PD). PD is caused by the xylem-dwelling pathogenic bacterium Xylella fastidiosa. We selected ten grapevines within this vineyard with a range of disease phenotypes, and monitored them over 2 growing seasons. We sampled each vines at key phenological stages (bloom, veraison, and post-harvest) and used an amplicon metagenomics approach to profile the bacterial (16S -V4) and fungal (ITS) communities of the sap. We identified a core microbiome of the sap composed of seven bacterial (Streptococcus, Micrococcus, Pseudomonas, Bacteroides, Massilia, Acinetobacter and Bacillus) and five fungal (Cladosporium, Mycosphaerella, Alternaria, Aureobasidium, and Filobasidium) taxa that were present throughout the growing season. Overall, the sap microbial makeup collected from canes was more similar to the root microbial profile. Alpha diversity metrics indicated a microbial enrichment at bloom and in vines with moderate PD severity suggesting a host-driven microbial response to environmental cues. Beta diversity metrics demonstrated that disease condition and plant phenology impacted microbial community profiles. Our study identified several potential taxonomic targets with antimicrobial and plant growth promoting capabilities that inhabit the grapevine sap and that should be further tested as potential biological control or biofertilizer agents.

Keywords: Vitis vinifera L., grapevine, sap, microbiome, Pierce's disease, Xylella fastidiosa, microbiome, xylem

\section{INTRODUCTION}

The vascular system ensures several key biological functions in plants. The xylem and phloem elements are major vehicles for water and nutrient transportation and signaling routes between the below (i.e., root) and above (i.e., leaf, fruit) ground plant parts. The xylem and phloem saps differ in chemical composition and their profile is also influenced by the plant phenological stages 
and environmental factors (Andersen et al., 1995; Lucas et al., 2013; Savage et al., 2016). In grapevine, the xylem sap is initially rich in sugars (especially glucose and fructose) and amino acids (especially glutamine) in the spring time right after the dormant season, because of the remobilization of nutrient reserves (e.g. starch) stored in the main permanent structure of the vine (Keller, 2010). This mobilization of nutrients is essential to support vegetative growth at bud-break until leaf becomes energy independent and transition from a sink to a source and export photosynthates and assimilates to the fruit via the phloem sap. To that end, research has focused on how irrigation and fertilization changed sap composition in order to maintain plant hydraulic function at maximum capacity and a balance between vegetative and reproductive growth (Peuke, 2000; El-Razek et al., 2011).

Several biotic and abiotic factors such as freeze damage, drought, and pathogen infection compromise the integrity of the grapevine vascular system and impair plant sap flux (Pouzoulet et al., 2014; Hochberg et al., 2017; Todaro and Dami, 2017). As a result the affected host shows a decrease in vigor and subsequently crop productivity and fruit marketability. One devastating vascular pathogen that plagues the California grapevine industry is Pierce's Disease (PD), caused by the gram-negative bacterium Xylella fastidiosa (Wells et al., 1987). Insect sharpshooters transmit $X$. fastidiosa to the host upon feeding events (Redak et al., 2004). Following infection, the bacterium systemically colonizes susceptible host and multiplies to high titer causing vascular occlusions and a loss of xylem conductivity (Deyett et al., 2019). As a result, grapevine decline rapidly displaying symptoms of canopy dwarfing and thinning as well as leaf scorching and berry raisining (Varela et al., 2001). In planta, X. fastidiosa resides exclusively in the lumen of the xylem vessel where the negative pressure, low oxygen and nutrient content selects for adapted microorganisms. However, very little is known about the microbial taxa that inhabit the grapevine sap, their population dynamic over a growing season and their interaction with $X$. fastidiosa. Wallis et al. (2013) showed that PD affected the grapevine sap chemical composition but no study has looked at microbial community shifts in response to pathogen infection and colonization of the host and during disease symptoms development.
Grapevine microbiome research has mainly focused on plant organ epiphytes (i.e., berry, leaf and root) because of its importance with grape production and specifically with regards to fruit and foliar diseases management as well as the biological significance of indigenous microbes with the regional signature of a wine (Bokulich et al., 2014; Perazzolli et al., 2014; Zarraonaindia et al., 2015). Identification of the microbial communities inhabiting the grapevine endosphere mocrobiome has been achieved using standard culture-dependent microbial techniques (West et al., 2010; Compant et al., 2011; Baldan et al., 2014; Dissanayake et al., 2018; Kraus et al., 2019). Cultureindependent amplicon metagenomic approaches have recently been deployed to improve the microbial profiling of the grapevine woody organs including trunk and cane (Faist et al., 2016; Deyett et al., 2017; Dissanayake et al., 2018). Unraveling the microbiome of the grapevine sap would provide a comprehensive view of the microbes that systemically move throughout the plant and would establish a framework for targeting biological control agents (BCAs) of vascular pathogens or plant growth promoting agents. Identifying BCAs that can control $X$. fastidiosa through direct inhibition or niche displacement and/or commensal and symbiotic organisms that can support the host immune system could become an integrated alternative approach to the current insect vector management strategy. Our research was designed to address this gap in the knowledge by characterizing the bacterial and fungal taxa that shape the xylem sap microbial communities and determining how the host phenology and PD severity impact microbial profile.

\section{MATERIALS AND METHODS}

\section{Sap Sample Collection}

Shoot samples were collected from a commercial vineyard in Temecula, California, subjected to high insect sharpshooter (the vector of $X$. fastidiosa) pressure. Ten grapevines were selected in 2016 on the basis on PD symptoms, with five healthy vines showing no or mild symptoms and five vines showing intermediate to severe symptoms (Figure 1). Canes were later
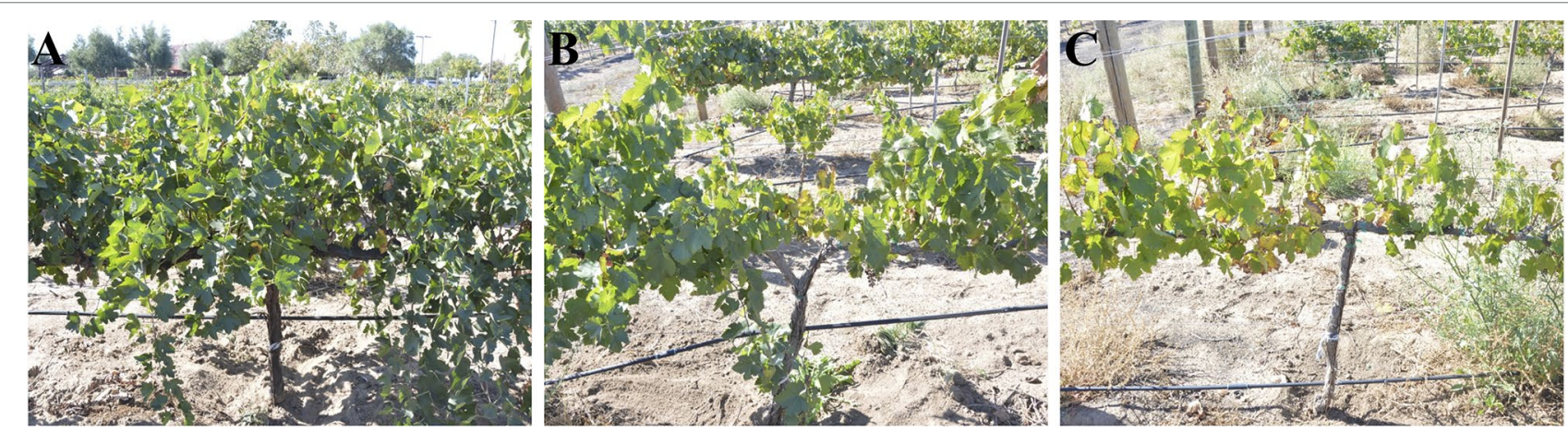

FIGURE 1 | Pierce's disease (PD) rating scale; (A) No symptoms or mild PD symptoms with only a few canes (<10\% of the canopy) showing marginal leaf scorching; (B) Moderate PD symptoms with visual dwarfing and thinning on 10-50\% of the canopy and/or canes displaying leaf scorching. The affected canes can also show green island and match-stick petioles and berry raisining late in the season. (C) Severe PD symptoms with 50-100\% of the vine canopy displaying dwarfing, thinning, leaf scorching and wood dieback. The affected canes showed green island and match-stick petioles and berry raisining late in the season. 
sampled in 2017 and 2018 at bloom (spring), veraison (summer) and post-harvest (fall) from the same grapevines. At each time point, three canes were pruned-off randomly along the grapevine cordons. In addition, grapevines were visually rated for PD symptoms at post-harvest using the same disease rating scale (no/mild, intermediate, or severe PD-symptoms; Figure 1). Canes were placed in a cooler with ice packs and brought back to the laboratory. On the same day of the sampling, canes were cut to $40 \mathrm{~cm}$ long, inserted in a Scholander pressure chamber (PMS Instruments, Albany OR) and pressurized to 400-550 PSI. Liquid sap was harvested from the end of the cane with a pipette and stored at $4^{\circ} \mathrm{C}$ until further processing. To obtain culturable sap microbiome, $20 \mu \mathrm{l}$ of sap was plated onto each of the following media: lysogeny broth (LB), trypticase soy agar (TSA), and potato dextrose agar (PDA). TSA and $\mathrm{LB}$ plates were stored at $28^{\circ} \mathrm{C}$ for 3-5 days and PDA plates at room temperature for 7 days. The bacteria and fungi recovered were sub-cultured to obtain single colonies and pure strains, respectively.

\section{DNA Extraction, PCR Condition, Library Preparation, and Sequencing}

The DNA was extracted from $250 \mu$ l of sap using the ZymoBIOMICS DNA miniprep kit per manufacturer's protocol (Zymo Research). The DNA was quantified using a Synergy HTX multi-mode reader (Biotek Instruments, Winooski, VT) for nucleic acid quantification. In addition, the DNA was extracted from pure bacterial colonies and fungal strains using Qiagen blood and tissue kit (Qiagen, Valencia, CA) following the manufacturer's instructions for cultured cells with an initial extended incubation time of 30 min instead of $10 \mathrm{~min}$.

The bacterial 16S and fungal ITS rRNA region was amplified for each DNA sample using the earth microbiome protocol and primers (http://www.earthmicrobiome.org/). Briefly, primers 515F and 806R with Caporaso barcodes were used for 16S amplification and ITS1f-ITS2 was used for fungal ITS amplification (Caporaso et al., 2010). Each sample was made in a $25 \mu \mathrm{l}$ PCR reaction using $10 \mu \mathrm{l}$ of Phusion hot start flex $2 x$ master mix, $0.5 \mu \mathrm{l}$ of primer $(10 \mu \mathrm{m})$ and $2 \mu \mathrm{l}$ of DNA. Thermal cycling parameters for ITS were $94^{\circ} \mathrm{C}$ for $1 \mathrm{~min} ; 35$ cycles of $94^{\circ} \mathrm{C}$ for $30 \mathrm{~s}, 52^{\circ} \mathrm{C}$ for $30 \mathrm{~s}, 68^{\circ} \mathrm{C}$ for $30 \mathrm{~s}$; followed by $68^{\circ} \mathrm{C}$ for $10 \mathrm{~min}$. Thermal cycling parameters for $16 \mathrm{~S}$ amplification were $94^{\circ} \mathrm{C}$ for $3 \mathrm{~min} ; 35$ cycles of $94^{\circ} \mathrm{C}$ for $45 \mathrm{~s}$, $50^{\circ} \mathrm{C}$ for $60 \mathrm{~s}, 72^{\circ} \mathrm{C}$ for $90 \mathrm{~s}$; followed by $72^{\circ} \mathrm{C}$ for $10 \mathrm{~min}$. Each PCR was accompanied with a negative control to ensure that the mastermix and barcodes were not contaminated. Samples were checked against a $1 \%$ agarose gel for visualization of appropriate band size. PCR products were quantified using a Synergy HTX multi-mode reader for nucleic acid quantification. Libraries were prepared by combining equal quantities of DNA from each sample. Libraries were cleaned using AMPure XP PCR purification system (Beckman Coulter) per manufacturer's protocol. Final concentration of libraries was quantified using qPCR and bioanalyzer before being sequenced on the MiSeq instrument (Illumina,
San Diego, USA) using 600-cycle (2X300 paired-end) V3 sequencing kit for fungal reads and the 500-cycle $(2 \times 250$ paired-end) V2 sequencing kit for $16 \mathrm{~S}$ at the UCR Genomics Core. Fungal and bacterial sequences were deposited in NCBI under the accession number PRJNA548584.

Culturable microbes were Sanger sequenced using the $27 \mathrm{~F} / 1392 \mathrm{R}$ primer pair of the $16 \mathrm{~S}$ bacterial gene (Turner et al., 1999) and ITS1/ITS4 primer pair for fungal ITS region (White et al., 1990). Each sample was made in a $25 \mu$ PCR reaction using $10 \mu \mathrm{l}$ of Phusion hot start flex $2 \mathrm{x}$ master mix, $0.5 \mu \mathrm{l}$ of each primer $(10 \mu \mathrm{M})$ and $2 \mu \mathrm{l}$ of DNA template. Thermal cycling parameters were $94^{\circ} \mathrm{C}$ for $2 \mathrm{~min} ; 35$ cycles of $94^{\circ} \mathrm{C}$ for $1 \mathrm{~min}$, $55^{\circ} \mathrm{C}$ for $30 \mathrm{~s}, 72^{\circ} \mathrm{C}$ for $1 \mathrm{~min}$; followed by $72^{\circ} \mathrm{C}$ for $5 \mathrm{~min}$. PCR product was visualized on a $1 \%$ agarose gel for appropriate band size, cleaned using Qiagen PCR Clean Up kit (Qiagen, Valencia, CA), quantified using Synergy HTX quantifier and submitted for Sanger sequencing at the UCR Genomics Core. Sequences were check for quality before using the NCBI BLAST database for identification.

\section{Computational Analyses}

Raw reads were first filtered for quality using sliding window 5:20 with trimmomatic (Bolger et al., 2014). Reads shorter than 125 bp were removed and low quality reads were filtered out. PhiX reads were then removed from the sequences. Due to the varying lengths of the fungal ITS reads, primers were removed using cutadapt version 1.18 and matching to primer sequences. Libraries were then demultiplexed using QIIME version 1.9.1 (Caporaso et al., 2010). DADA2 version 1.6.0 (Callahan et al., 2016) in $\mathrm{R}$ version 3.4.4 was used for the remainder of the processing. Within DADA2, sequences were filtered to contain no ambiguous base calling, and no more than two errors. $16 \mathrm{~S}$ reads were fixed at lengths for $240 \mathrm{bp}$. Reads were then de-replicated, and further filtered using the sample inference algorithm and learned error rates within the DADA2 pipeline. Paired end reads were merged using standard arguments. Chimeric sequences were also filtered out. Taxonomy was assigned using the Unite database version 10.10.2017. DADA2 method creates ASV (amplicon sequence variant, similar to operational taxonomic units or OTUs, but is capable of resolving amplicons to a single nucleotide) and thus may make species level identification when $100 \%$ of sequences match to reference (Callahan et al., 2016). Bacteria identification was realized using the IDTAXA classification against the SILVA SSU r132 reference database. ClustalW and maximum likelihood parameters were used to create a bacterial tree for UniFrac metrics.

Data were then inputted into the phyloseq package version 1.22.3 (McMurdie and Holmes, 2013). Microbes unidentified at the kingdom and phylum level or classified as plant or other contaminants were removed for both datasets. Phyla that did not occur in at least $5 \%$ of samples were removed as well as singletons, doubletons and taxa that only occurred in one vine. Samples that had too few reads were also removed. For analysis, comparing disease severity, only the post-harvest time points were used. For taxonomy charts, libraries were aggregated to the genus level and transformed to relative abundance. Fungal 
and bacterial genera were filtered to the $0.1 \%$ level. SunburstR version 2.1.0 was utilized to visualize the taxonomy pie charts. Statistical differences between genera in the Xanthomonadaceae were computed using Kruskal-Wallis and pairwise comparisons where done with Wilcox pairwise test. Prevalence Venn diagrams was used to identify unique taxa that were more likely associated with the specific grapevine phenological stages at the different sampling time point and with specific disease condition. We set stringent filters with taxa needed to occur in at least $50 \%$ of the samples in a given category. UpSetR version 1.3.3 was used to create graphical representation of prevalence Venn diagrams.

Using the number of unique families as a proxy for alpha diversity, mean and standard error were calculated for each time point grouping. Error bars represent standard error of the mean. Statistics on count of family were determined by generalized linear model using Poisson regression and statistical significance on pairwise comparison were conducted through Tukey's test using the multcomp package version 1.48 . To look at the difference between groupings, beta-diversity plots were created using weighted UniFrac and PCoA metrics for bacteria and Bray-Curtis dissimilarity matrix and NMDS ordination matrix for fungi using the vegan package version 2.4-5. Adonis test with 999 permutations were run to determine statistical differences among centroids. Pairwise comparisons were calculated with the RVAideMemoire package version 0.9-71. To find differentially abundant microbe associated with season or condition, DeSeq2 was used. Microbes that occurred in more than one sample and in more than one year were used in the analysis. Random Forests supervised machine learning algorithm was applied to the dataset to learn a function that relates predictors (ASVs) to classification, here phonological stage and disease condition (Breiman 2001). Random Forest creates a function using part of the dataset to train and validates that function by classifying the remaining subset of samples. ASVs are assigned with an importance score, which indicates the increase in the functions error rate if the taxa would be removed. In this way, microbes with a high importance score are valuable predictors for a classification. Random forest was carried out using package randomForest version 4.6-14.

\section{RESULTS}

Dada2 analysis revealed that there were 2,875 bacterial amplicon sequence variants (ASVs) and 2,694 fungal ASVs in 68 sap samples (two samples were removed based on poor quality sequences). After removal of contaminants, singletons, doubletons and taxa that did not occur in at least 5\% of the samples, there were 168 fungal ASVs and 390 bacterial ASVs. Sap samples that did not have at least 500 reads were removed from the analyses. After filtering, we used a total of 61 samples from the bacterial dataset including 26 from post-harvest, 15 from bloom and 20 from veraison and a total of 65 samples from the fungal dataset including 29 from post-harvest, 16 from bloom, and 20 from veraison.
Phylogeny and relative abundance of fungal and bacterial taxa were represented in a Sunburst plot (http://rpubs.com/ edeye001/487241). Results showed that fungal communities were dominated by the Ascomycota phylum ( 92\%) and the remaining was composed with the phylum Basidiomycota $(\sim 8 \%)$. Cladosporium represented over half $(\sim 56 \%)$ of the total fungal genera followed by Mycosphaerella ( 16\%) and Alternaria $(\sim 9 \%)$. Filobasidium ( $\sim 6 \%)$ was the major genus among the Basidiomycota. The sap culturable mycobiome indicated that Cladosporium was also the main fungus recovered and also included the taxa Filobasidium and Mycosphaerella. The bacterial community composition was more diverse than the fungal community. Proteobacteria ( 54\%) was the major phylum, followed with Firmicutes ( 24\%), Actinobacteria ( 12\%), and Bacteroidetes ( 8\%). At the genus level an unidentified genus in the Enterobacteriaceae family was most abundant $(\sim 19 \%)$. Streptococcus represented ( 10\%) followed with Bacteroides ( 6\%), Bacillus ( 6\%), Acinetobacter ( 4\%) and Pseudomonas $(\sim 3 \%)$. The culturable bacteria were mostly in the genus Bacillus, but Paenibacillus, Virgibacillus, Curtobacterium, and Micrococcus were also re-isolated.

The Xanthomonadaceae (the family that X. fastidiosa belongs to) represented $3 \%$ of the overall dataset and was comprised of three genera, Stenotrophomonas ( 2\%), Xylella ( 0.5\%), and Pseudoxanthomonas (0.5\%). Xylella, the causal agent of PD, was found at low frequencies and low incidence (11 samples total) and mostly at post-harvest (eight samples of the total 26 post-harvest samples $=31 \%$ ). Xylella was also detected at bloom (one sample) and veraison (two samples). Relative abundance of Xylella at the postharvest time point was only significantly higher $(P<0.05)$ in vines showing moderate $\mathrm{PD}$ symptoms compared to healthy vines (i.e., showing mild or no symptoms; Figure 2). Stenotrophomonas incidence and abundance was the highest in healthy vines although not statistically different from the other disease conditions.

Alpha-diversity showed that there were approximately twice as many bacterial than fungal families in grapevine sap (Figure 3A). Bacterial family richness increased significantly at post-harvest in aging grapevines between 2016-17 and 2018 ( $P$ $<0.001$ ). In addition, bloom and veraison time-points displayed significant higher family richness compared to post-harvest in both years for bacteria $(P<0.001)$ and in 2018 for fungi $(P<$ $0.01)$. Moreover, vine condition impacted microbial diversity (Figure 3B). Vines categorized as moderately PD symptomatic at post-harvest harbored significantly higher number of bacterial and fungal families compared to mildly symptomatic vines $(P<$ $0.05)$. Severely symptomatic vines also had significantly fewer unique bacterial families compared to moderately symptomatic vines $(P<0.05)$.

Weighted UniFrac of bacterial beta-diversity plots (Figure 4A) indicated a significant clustering due to the year of sampling $(P<0.001)$ and the time of sampling in a given year $(P<0.01)$. Pairwise PERMANOVA revealed that bloom was distinct from the other two phonological stages $(P<0.05)$ and that 2018 was distinct from 2016 and $2017(P<0.01)$. Fungal Bray-Curtis beta-diversity plots (Figure 4B) indicated that both 


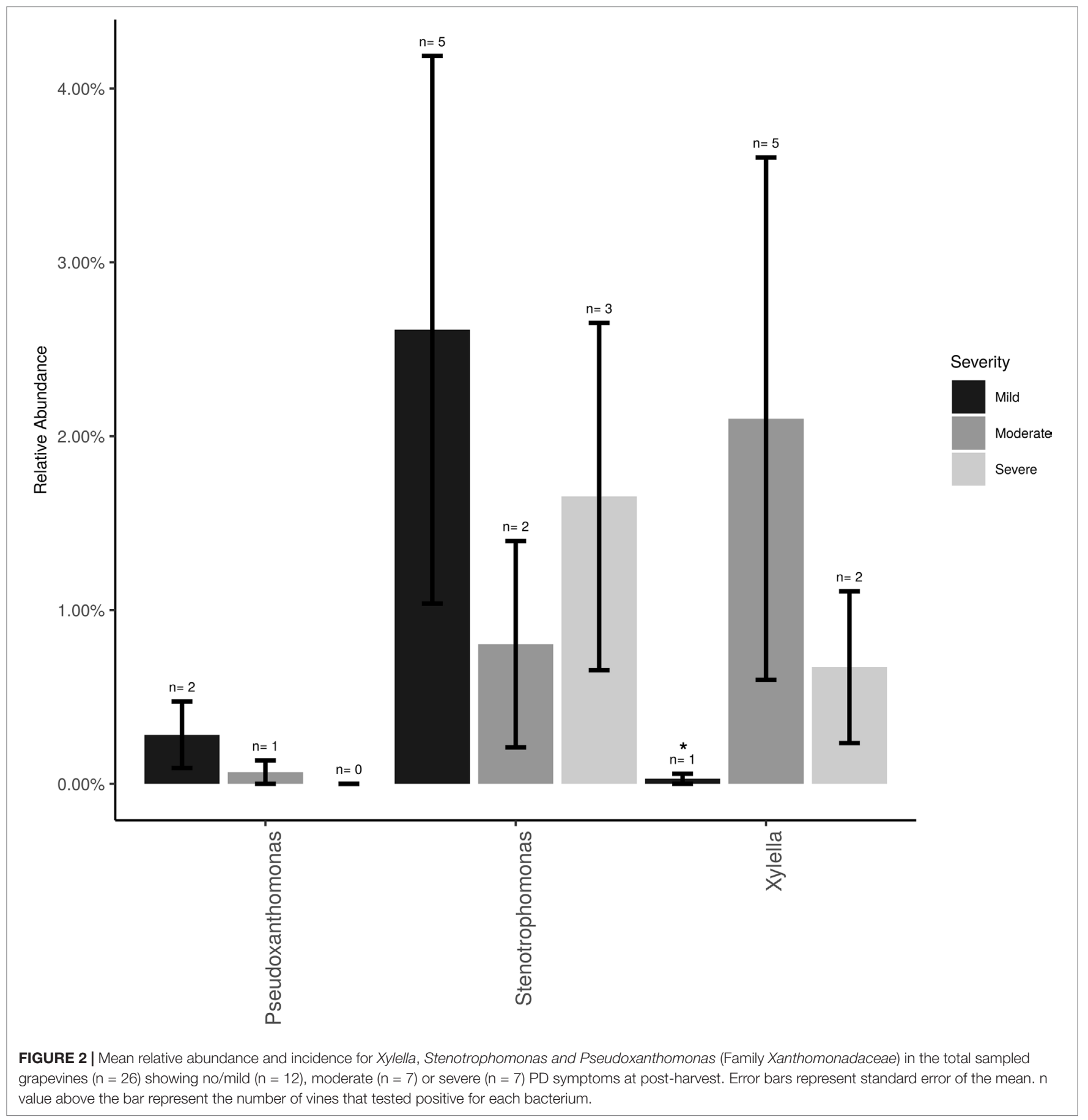

year of sampling $(P<0.01)$ and time of sampling $(P<0.01)$ were significantly different in the clustering of fungal communities. There was a strong clustering of the samples collected at postharvest for all three years in comparison to other sampling year and time. A pairwise PERMANOVA revealed that postharvest was significantly different to both bloom and veraison $(P<0.05)$ and 2018 was significantly different from both 2017 and 2016, and that 2016 was significantly different than $2017(P<0.05)$. Prevalence Venn diagrams indicated that seven bacteria (Streptococcus, Micrococcus, Pseudomonas, Bacteroides, Massilia, Acinetobacter and Bacillus) and five fungi (Cladosporium, Mycosphaerella, Alternaria, Aureobasidium, and Filobasidium) were ubiquitous across season at all three plant phenological stages (Figure 5). In contrast, other taxa were more likely associated with specific seasonal time points likely contributing for the significant differences in alpha diversity (Figure 3A). Hence, Sphingobium, Novosphingobium, Methylobacterium and Streptomyces were more specific to 

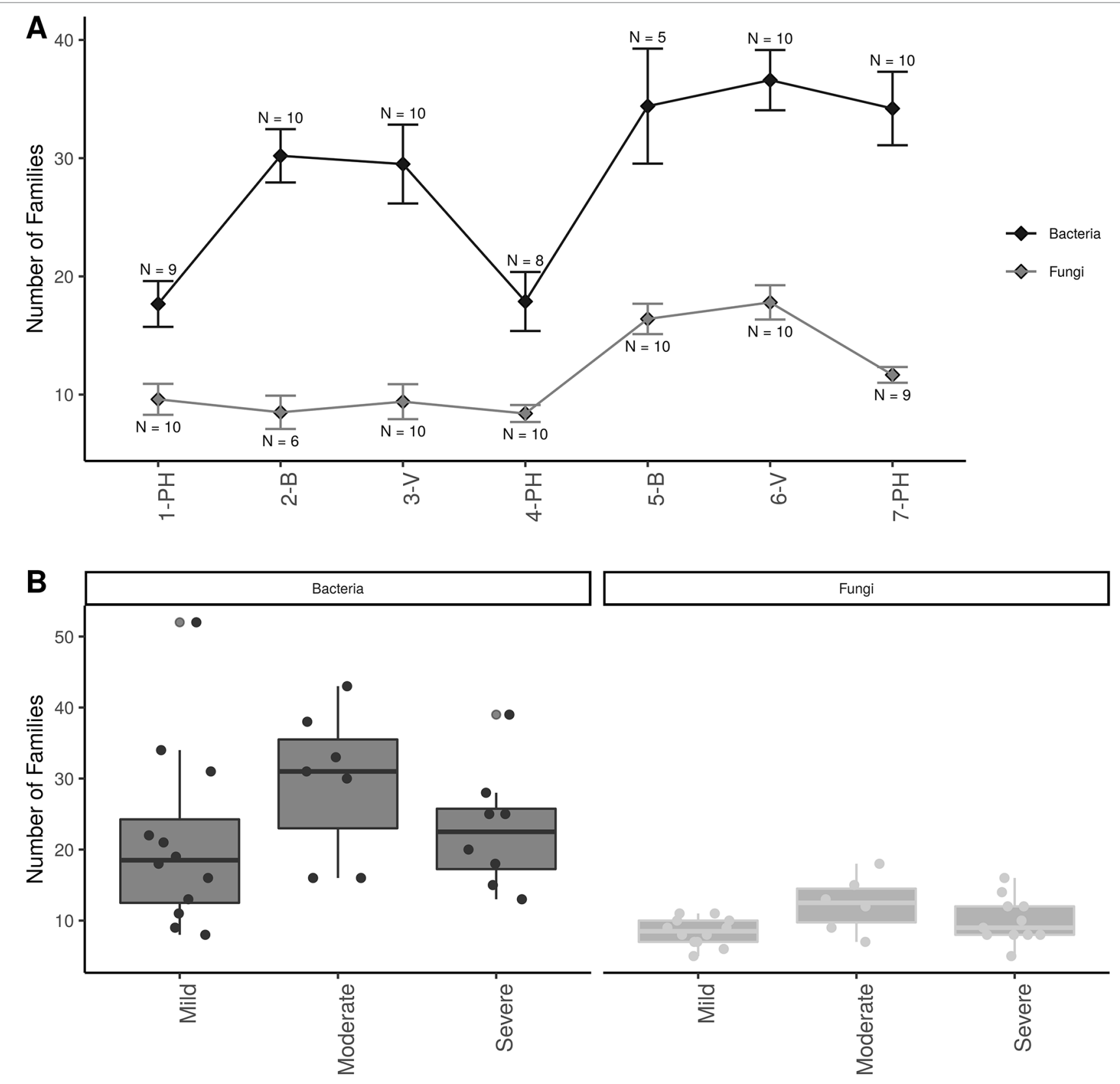

FIGURE 3 | Alpha diversity plots; (A) Familial richness in bacterial and fungal sap microbiomes across seasonal timepoints; 1-PH : post-harvest 2016, 2-B : bloom 2017, 3-V: veraison 2017, 4-PH : post-Harvest 2017, 5-B : bloom 2018, 6-V: veraison 2018, and 7-PH : post-harvest 2018. Timepoint scheme is the same across graphs. Error bars represent standard error of the mean. $\mathrm{n}$ values represented the number of samples for each time point. (B) Number families in bacterial and fungal within different disease conditions at the $\mathrm{PH}$ time point. Point represent individual samples.

bloom and Actinomyces, Neisseria, and Hygrogenophilus to veraison. We used Random Forest analyses to identify predictors (fungal and bacterial taxa) responsible for the clustering in the beta-diversity metrics (Figure 4) and identified that the most abundant taxa (Alternaria, Cladosporium, Filobasidium, Mycosphaerella, Streptococcus, Micrococcus, Bacteroides and unknown Enterobacteriaceae) were the likely drivers (Figure 6).

In order to evaluate the impact of disease on microbial communities, we only considered taxa from the post-harvest time points. Beta diversity weighted UniFrac metrics showed that bacterial community clustering was significantly affected by disease severity $(P<0.05$; Figure 7A). In addition, Bray-Curtis metrics indicated that fungal clustering was not affected by disease condition of the vines but was rather attributed to year $(P<0.05$; Figure 7B). Prevalence Venn diagrams showed that several microbes identified in the core microbiome were also found across all grapevines regardless of their disease condition (Figure 8). In addition, eleven bacteria (Corynebacterium, 


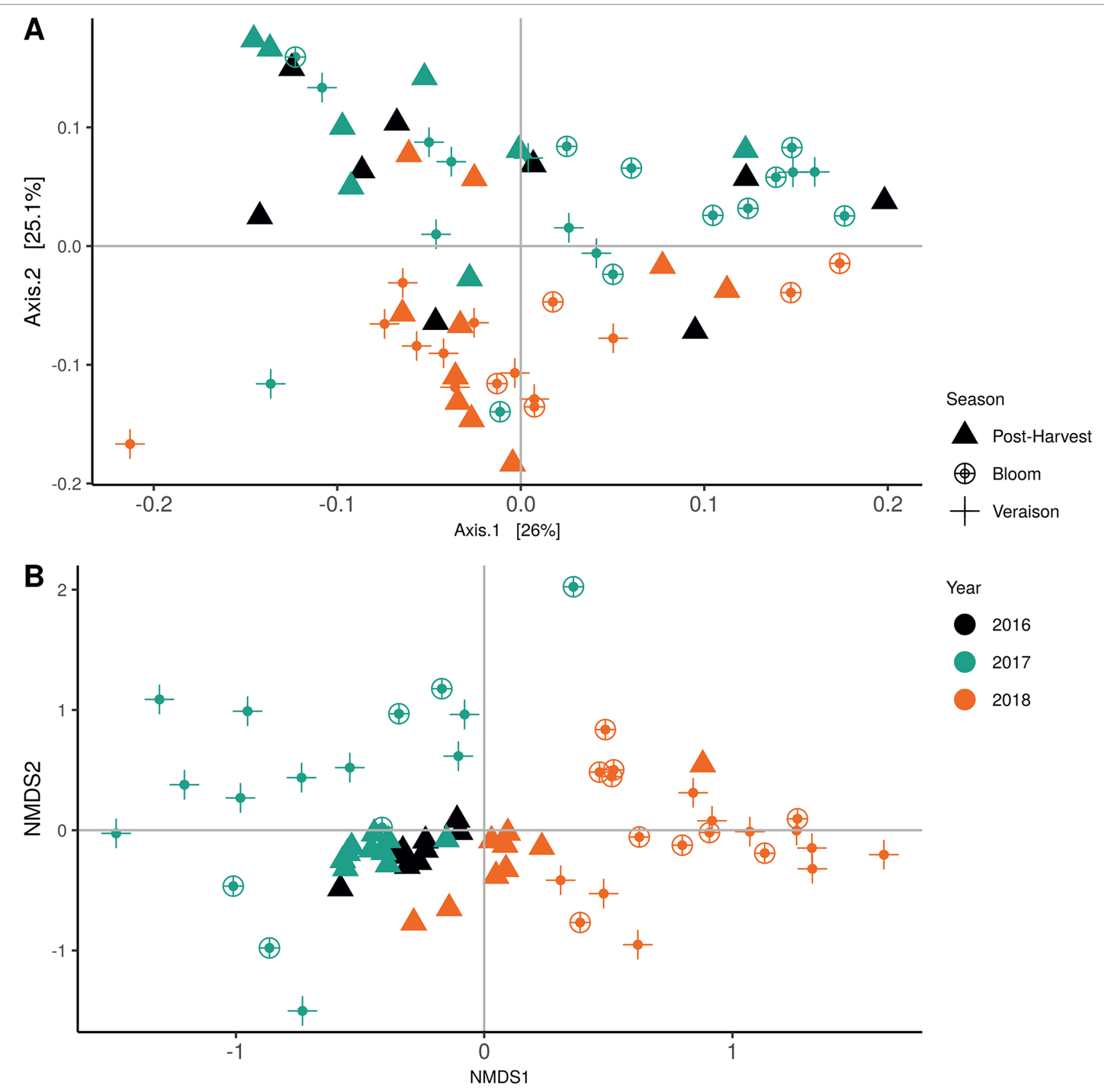

FIGURE 4 | Beta diversity plots for seasonal time points based on: (A) Weighted UniFrac distance for bacteria and (B) Bray-Curtis dissimilarity for fungi. Points represent one vine community. Point are colored by year, shaped by season.

Methylobacterium, Rothia, Actinomyces, Meiothermus, Neisseria, Ralstonia, Xylella, Hydrogenophilus, Gemella, and Pseudomonas) were specific to moderate PD symptoms severity likely contributing to the significant differences in alpha diversity (Figure 3B). Random Forest analysis suggested that the clustering in bacterial beta-diversity metrics (Figure 7A) was driven by the most abundant bacterial taxa (Streptococcus, Pseudomonas, Micrococcus, Bacteroides and unknown Enterobacteriaceae), disease condition-specific taxa (Rothia and Meiothermus) and the pathogen Xylella (Figure 9).

\section{DISCUSSION}

This culture-independent amplicon-based metagenomics microbiome study establishes a reference framework for the bacterial and fungal communities living in the xylem sap of grapevine and captures temporal microbial shifts during the annual cyclic changes of the host phenology. In addition, it provides insightful information about the impact of the xylemdwelling pathogen $X$. fastidiosa on the microbiome profile of the grapevine sap. 


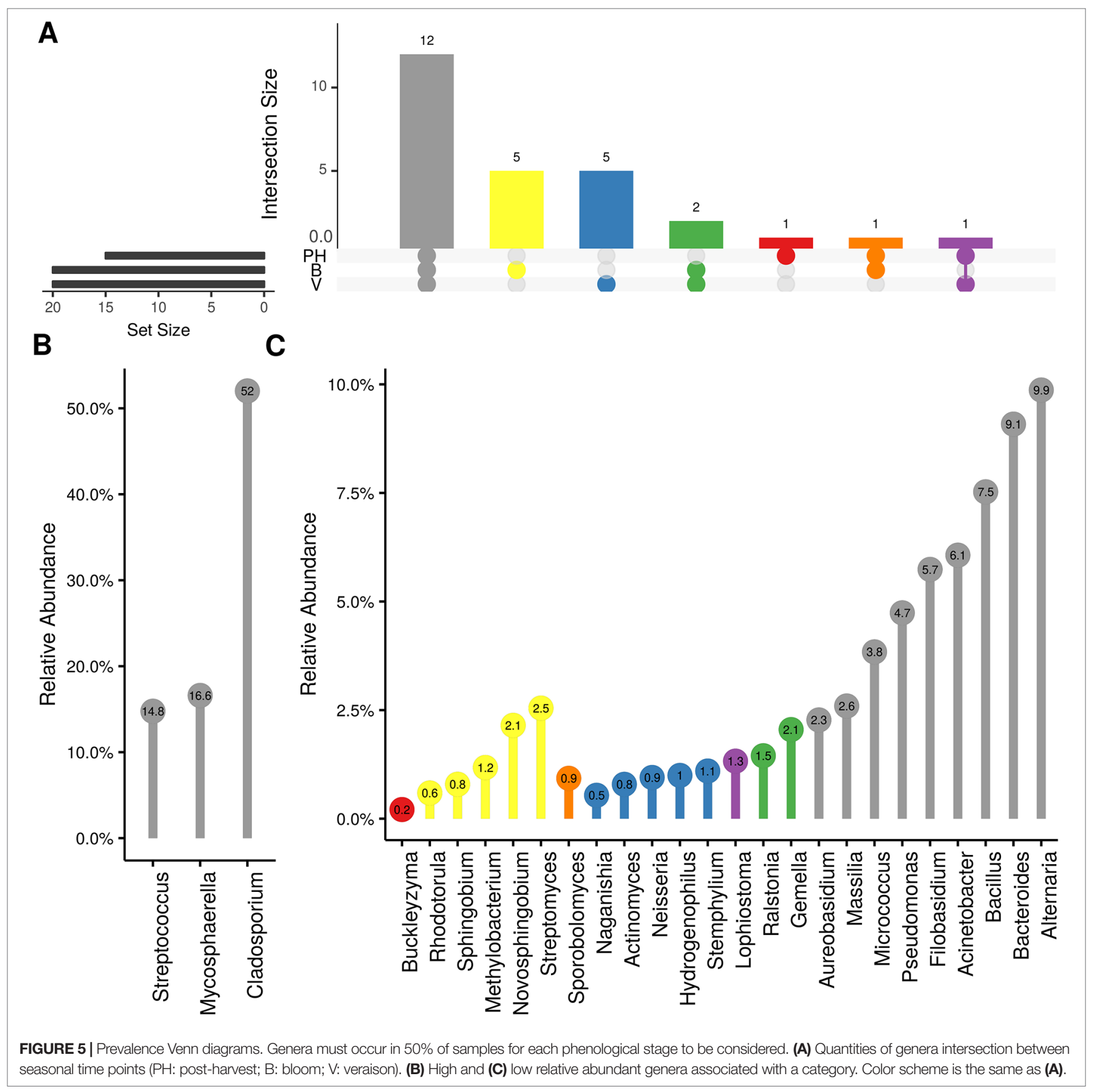

The grapevine sap mycobiome was most exclusively composed of taxa in the Ascomycota in addition to a few yeasts from the phylum Basidiomycota. The sap bacteriome was similar to that of other biocompartments with a high abundance of Proteobacteria, and lower abundance of Firmicutes, Actinobacteria, and Bacteroidetes (Zarraonaindia et al., 2015; Faist et al., 2016; Deyett et al., 2017; Marasco et al., 2018). Noticeably, no Acidobacteria were detected, whereas it was a significant member of the rhizosphere, and root endosphere community in other studies. However, the sap microbiome profile at the phylum level was more similar to the root than the cane, despite the fact that the sap was collected from the later tissue. In addition, we found evidence for the presence of many genera known to be associated with rhizosphere and root endosphere (Rhizobium, Streptomyces, and Pseudomonas) including several pathogenic fungi known to cause root diseases (Campylocarpon, Ilyonectria, Fusarium) (Brum et al., 2012; Cabral et al., 2012). Together these data support the evidence that the microbial makeup of the sap is of belowground origin. This result is in line with a report from another perennial crop (Fausto et al., 2018). However, one should also consider that some organisms, such as $X$. fastidiosa, can also be introduced to the host vascular system by insect feeding and 
A

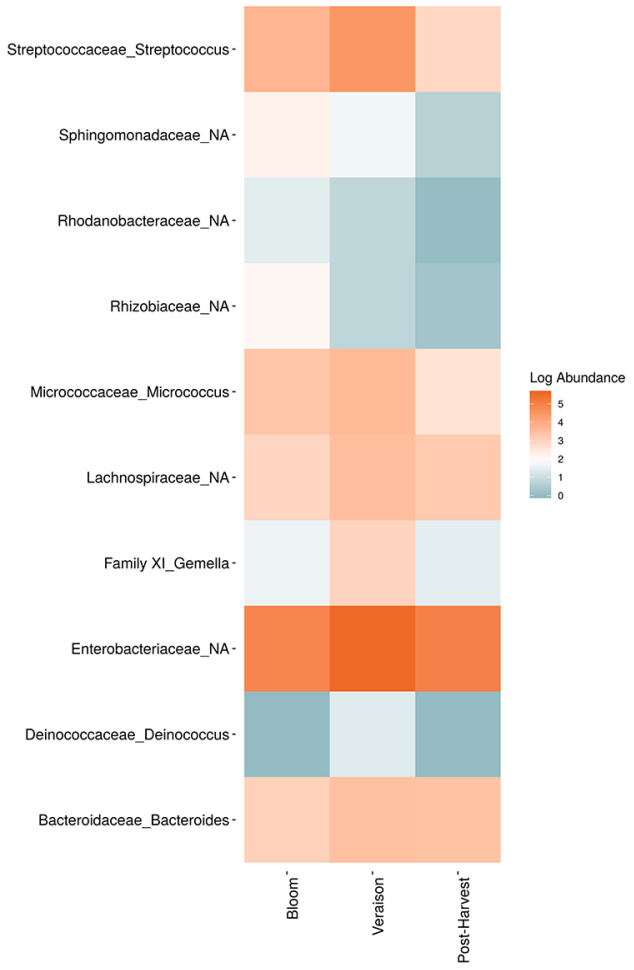

B

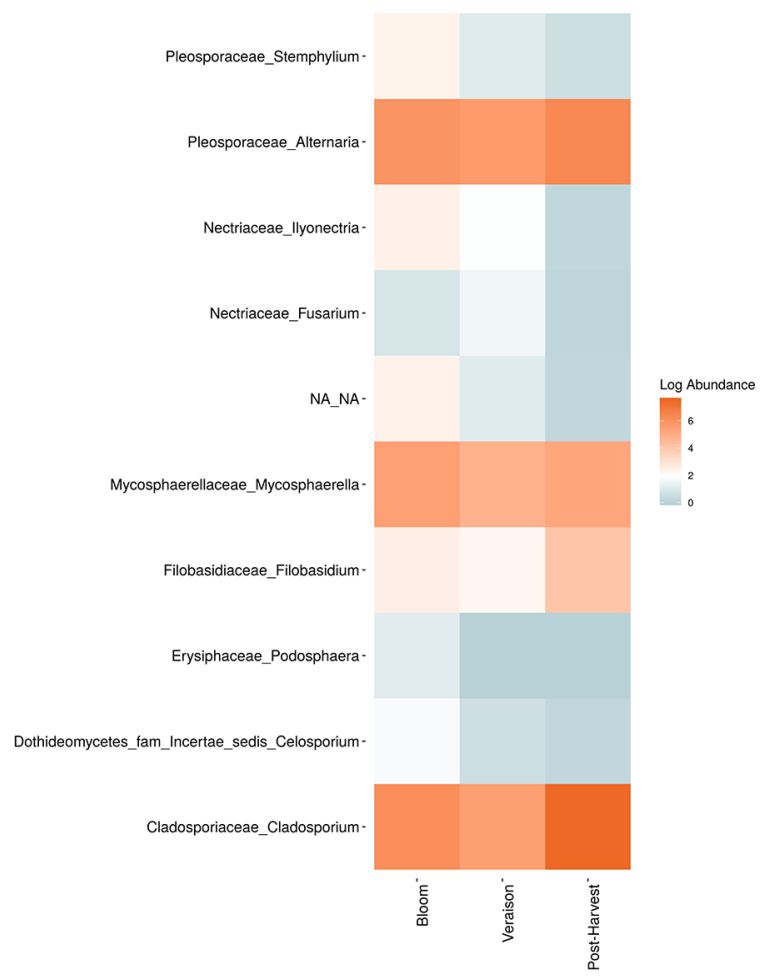

FIGURE 6 | Log abundance of the top 10 random forest important genera for (A) Bacteria and (B) fungal across seasonal time points.

become part of the sap microbiome (Redak et al., 2004; LopezFernandez et al., 2017), while other airborne microbes may enter the plant endosphere through wounds, and plant surfaces via stomatas (Compant et al., 2011).

The core microbiome of grapevine sap, that was defined as the microorganisms that occurred in at least $50 \%$ of all samples regardless of seasonal time points, was composed of seven bacterial (Streptococcus, Massilia, Bacteroides, Micrococcus, Pseudomonas, Acinetobacter and Bacillus) and five fungal (Cladosporium, Mycosphaerella, Alternaria, Aureobasidium, and Filobasidium) taxa. Together, these make up over $51 \%$ and $92 \%$ of the bacterial and fungal datasets, respectively. Pseudomonas, Bacillus, Micrococcus, Acinetobacter, Cladosporium, Aureobasidium Mycosphaerella, Filobasdium and Alternaria have been identified in and/or on many plants organs of grapevine (West et al., 2010; Compant et al., 2011; Baldan et al., 2014; Brysch-Herzberg and Seidel, 2015; Deyett et al., 2017; Dissanayake et al., 2018; Kraus et al., 2019; Nigris et al., 2018). More surprising bacterial taxa included Massilia, Bacteroides and Streptococcus. Streptococcus is a facultative-anaerobe bacterium and a well-studied human pathogen. However, it was previously found to be associated with many grapevine biocompartments (soil, root, grape leaf) and across several viticulture areas (Zarraonaindia et al., 2015). Massilia is an aerobic bacterium found in a range of habitats (i.e., desert, glacier, water and soils) and was reported to colonize the rhizosphere of plants (Ofek et al., 2012). Bacteroides is an anaerobic bacterium that metabolize mono or polysaccharides and is known to colonize the guts of animals and survive in water habitats (Wexler, 2007). One should consider that the more unique bacteria (Massilia, Bacteroides), might be specific to the viticulture region, because of the water and soil properties. As previously demonstrated for grapevine epiphytes (Bokulich et al., 2014), each viticulture area possess unique indigenous microbial taxa that shape the characteristics of the region, and our data suggests that this paradigm also applies to endophytic microbes. For the other core microbiome taxa, the fact that several of them have been found in association with many grapevine biocompartments both as epiphytes and endophytes, suggest that those could use xylem (and perhaps phloem) as transport routes as previously suggested (Compant et al., 2010; Compant et al., 2011).

Our alpha and beta-diversity metrics showed that the sap microbiome assemblage was shaped by both the plant phenology and disease condition, although the later mainly affected bacterial communities. One should not rule out that the other vascular pathogens also detected in this study (i.e., Campylocarpon, Ilyonectria, Fusarium) may have increased background noise in our analyses. Interestingly we measured a peak in microbial richness during bloom, a key phenological stage for pollination and fertilization. Especially four taxa surfaced at this time point (Streptomyces, Rhodotula, Sphingobium and Novosphingobium), and those are known to possess plant growth promoting capabilities (El-Tarabily, 2004; Hahm et al., 2012; Seipke et al., 2012; Kim et al., 2019), suggesting that the plant could recruit microbes to participate in key physiological processes. Similarly, vines with moderate PD symptoms displayed higher microbial diversity than in either healthy or severely symptomatic vines. Plants are known to drive microbial assemblage in order to cope with biotic or 


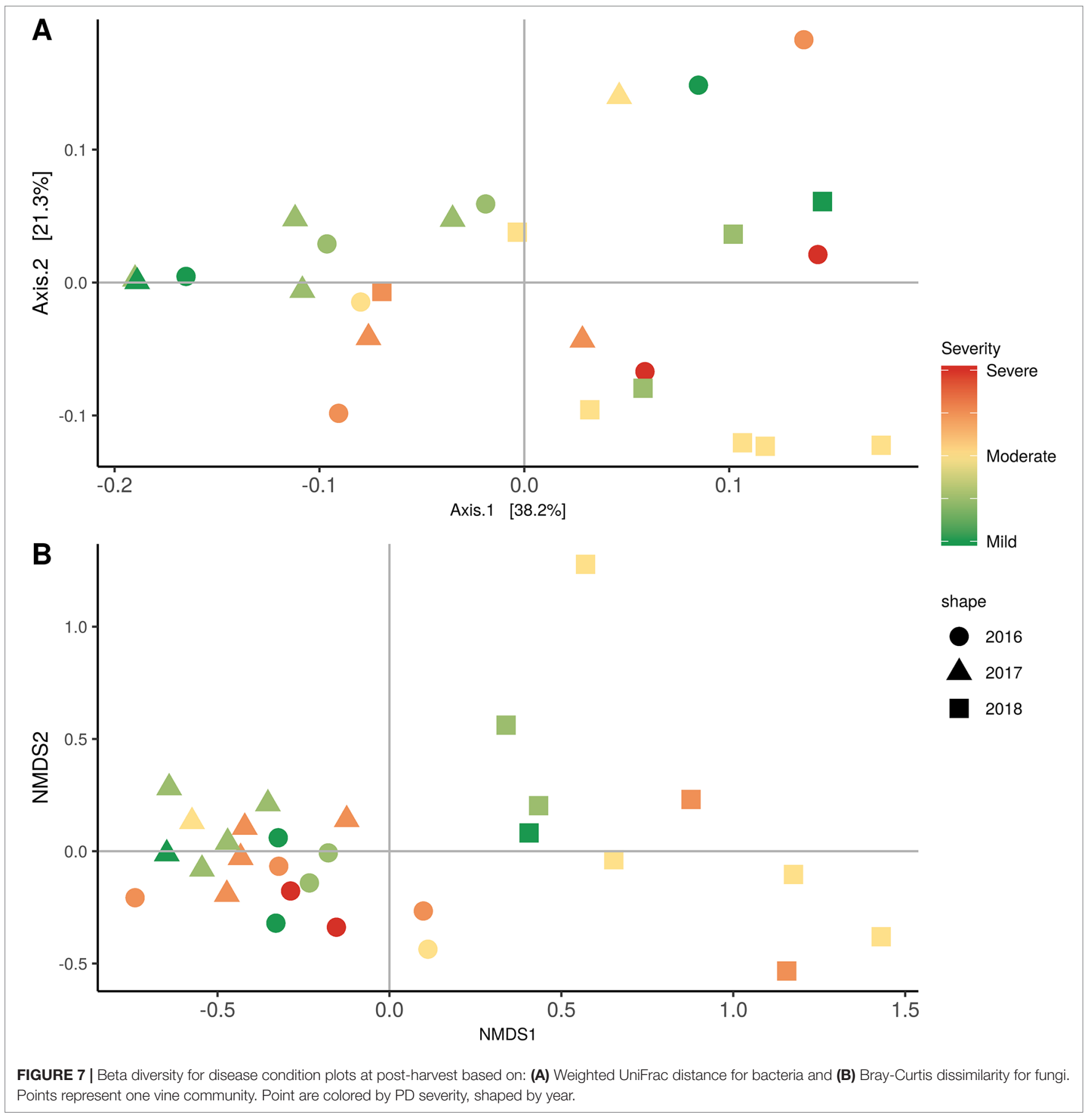

abiotic stresses and increase environmental fitness (Berendsen et al., 2012; Turner et al., 2013). Perhaps our data indicated a plantdriven microbial response to the pathogen infection. In contrast, in severely symptomatic vines, the toxic environment (e.g., occlusion of xylem vessel with tyloses and decrease of hydraulic conductivity; Deyett et al., 2019) is not conducive to microbial survival.

Asymptomatic grapevines at post-harvest displayed overall a lower pathogen incidence and abundance. The relatively low incidence of $X$. fastidiosa $(\sim 31 \%)$ measured in vines exacerbating PD symptoms was comparable to a previously published report
(Deyett et al., 2017). These results can be attributed to the sampling design (only 3 canes per vine canopy), the heterogeneous distribution of $X$. fastidiosa in the vine canopy and the occlusion of vessels in severely symptomatic vines make it challenging to recover the bacterium (Deyett et al., 2019). Interestingly, Stenotrophomonas abundance was inversely proportional to that of Xylella in all three PD rating categories. Stenotrophomonas is a closely related bacterium to Xylella but is known to benefit grapevine by acting as a biofertilizer and biocontrol agent to nematodes (Aballay et al., 2011; Karagoz et al., 2012). Pseudomonas 


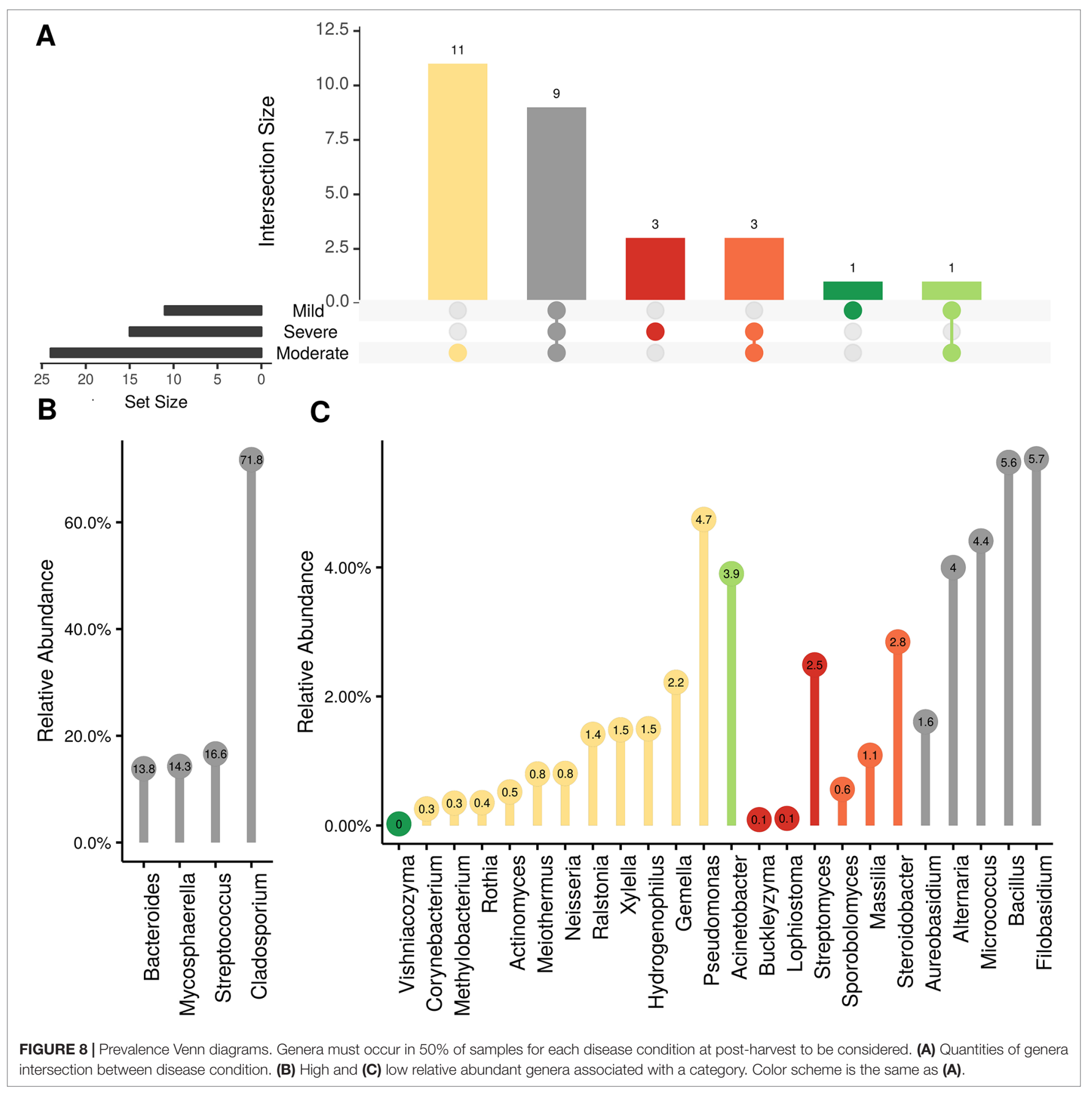

was also found in vines with moderate PD symptoms, although this was a much lower abundance $(\sim 5 \%)$ than previously reported ( 80\%) from grapevine canes (Deyett et al., 2017; Faist et al., 2016). As previously discussed, Pseudomonas likely originates from the roots and colonizes the developing vegetative organs early in the growing season, but unlike most of the other microbial inhabitants of the sap, it appears to have the ability to become established in the lignified structural component of the grapevine vascular system. Deyett et al. (2017) showed that Pseudomonas correlated negatively with Xylella in PD-affected vines, suggesting that it could be used as a biocontrol agent given its known properties for secreting antimicrobial and plant growth promoting compounds (Khmel et al., 1998; Loper et al., 2012; Pieterse et al., 2014; Gruau et al., 2015). Paraburkholderia phytofirmans (formerly known as Burkholderia phytofirmans) has also been recognized as a potential biocontrol agent to grapevine PD because it has been identified as an endophyte of grapevine leaf and showed the ability to colonize the grapevine endosphere upon inoculation (root, vascular system and leaf) and prime host disease resistance pathways (Compant et al., 2005; Compant et al., 2008; Lo Piccolo et al., 2010; Baccari et al., 2019). Our data did not support the presence of this specific bacterium in the sap of grapevine but 
Xanthomonadaceae_Xylella-

Thermaceae_Meiothermus -

Streptococcaceae_Streptococcus -

Pseudomonadaceae_Pseudomonas -

Micrococcaceae_Rothia -

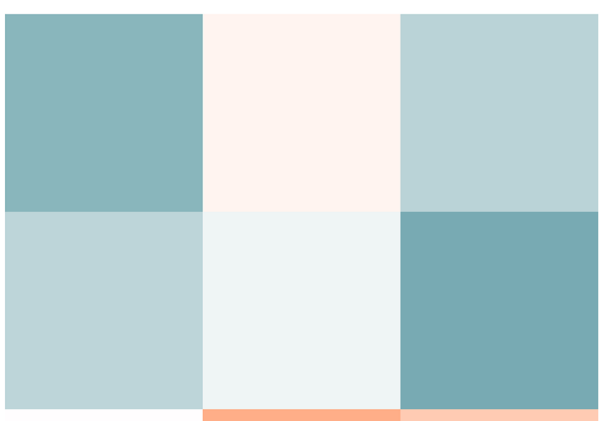

Log Abundance

Micrococcaceae_Micrococcus-
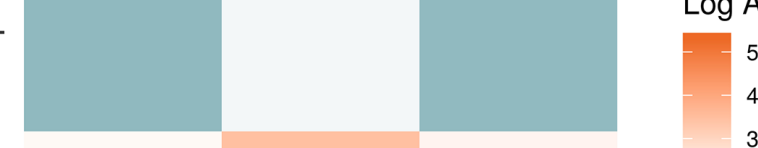

Lachnospiraceae_NA-

Enterobacteriaceae_NA

\section{Dietziaceae_Dietzia -}

Bacteroidaceae_Bacteroides -

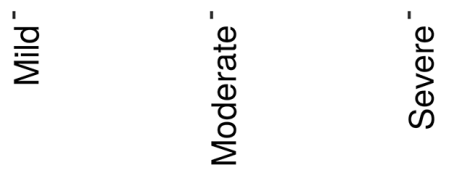

FIGURE 9 | Log abundance of the top 10 random forest important genera for (A) Bacteria and (B) fungal across disease conditions at post-harvest. 
identified several taxa from the family Burkholderiaceae ( $5 \%$ abundance), including Massilia and Ralstonia that were a part of the core microbiome and a biomarker for vines showing moderate PD-symptoms, respectively. Finally, Methylobacterium also surfaced as a common bacteria in grapevines with moderate PD symptoms. Araujo et al., (2002) described that in the Citrus Variagated Chlorosis (CVC) pathosystem, Xylella fastidiosa subsp. pauca and Methylobacterium acted in synergy and caused an increase in disease severity. Our data support the evidence that Methylobacterium is an endophyte of grapevine and that perhaps similar synergistic mechanisms occur in the CVC and PD pathosystems.

This study highlights several potential fungal and bacterial targets with antimicrobial and plant growth promoting properties. Future studies should focus on isolating those potentially beneficial strains and test their biological functions in vitro and in planta bioassays. The broad host range of $X$. fastidiosa combined with the movement of plant material has led to the introduction of the pathogen to new agricultural areas and made it an emerging global threat (Rapicavoli et al., 2018; Sicard et al., 2018). PD management strategies has relied most exclusively on vector control and the breeding of PD-resistant varieties in grapevine (Krivanek et al., 2006; Daugherty et al., 2015). Few resources have been invested in developing commercial bioproducts that do not select for disease resistance or cause environmental pollution. We hope that

\section{REFERENCES}

Aballay, E., Martensson, A., and Persson, P. (2011). Screening of rhizosphere bacteria from grapevine for their suppressive effect on Xiphinema index Thorne \& Allen on in vitro grape plants. Plant Soil 347, 313-325. doi: 10.1007/ s11104-011-0851-6

Andersen, P. C., Brodbeck, B. V., and Mizell, R. F. (1995). Diurnal-variations in tension, osmolarity, and the composition of nitrogen and carbon assimilates in xylem fluid of Prunus-persica, Vitis hybrid, and Pyrus-communis. J. Am. Soc. Hortic. Sci. 120, 600-606. doi: 10.21273/JASHS.120.4.600

Araujo, W. L., Marcon, J., Maccheroni, W., van Elsas, J. D., van Vuurde, J. W. L., and Azevedo, J. L. (2002). Diversity of endophytic bacterial populations and their interaction with Xylella fastidiosa in citrus plants. Appl. Environ. Microb. 68, 4906-4914. doi: 10.1128/AEM.68.10.4906-4914.2002

Baccari, C., Antonova, E., and Lindow, S. (2019). Biological control of Pierce's disease of grape by an endophytic bacterium. Phytopathology 109, 248-256. doi: 10.1094/PHYTO-07-18-0245-FI

Baldan, E., Nigris, S., Populin, F., Zottini, M., Squartini, A., and Baldan, B. (2014). Identification of culturable bacterial endophyte community isolated from tissues of Vitis vinifera "Glera". Plant Biosyst. 148, 508-516. doi: 10.1080/11263504.2014.916364

Berendsen, R. L., Pieterse, C. M. J., and Bakker, P. A. H. M. (2012). The rhizosphere microbiome and plant health. Trends Plant Sci. 17, 478-486. doi: 10.1016/j. tplants.2012.04.001

Bokulich, N. A., Thorngate, J. H., Richardson, P. M., and Mills, D. A. (2014). Microbial biogeography of wine grapes is conditioned by cultivar, vintage, and climate. Proc. Natl. Acad. Sci. U. S. A. 111, E139-E148. doi: 10.1073/ pnas. 1317377110

Bolger, A. M., Lohse, M., and Usadel, B. (2014). Trimmomatic: a flexible trimmer for Illumina sequence data. Bioinformatics 30, 2114-2120. doi: 10.1093/ bioinformatics/btu170

Breiman, L. (2001). Random forests. Mach. Learn. 45, 5-32. doi: 10.1023/A:1010933404324

Brum, M. C. P., Araujo, W. L., Maki, C. S., and Azevedo, J. L. (2012). Endophytic fungi from Vitis labrusca L. ('Niagara Rosada') and its potential for the this microbiome approach will lay the foundation for innovative research and lead to novel product development and marketing.

\section{DATA AVAILABILITY STATEMENT}

Fungal and bacterial sequences were deposited in NCBI under the accession number PRJNA548584.

\section{AUTHOR CONTRIBUTIONS}

ED designed the experiment, collected and analyzed the data, and co-wrote the manuscript. PR conceived the original project and research plans and co-wrote the manuscript.

\section{FUNDING}

We would like to acknowledge the USDA National Institute of Food and Agriculture Hatch Projects 233883 for funding support.

\section{ACKNOWLEDGMENTS}

We would like to thank Wiens Vineyard, Temecula, CA, for providing a research site.

biological control of Fusarium oxysporum. Genet. Mol. Res. 11, 4187-4197. doi: 10.4238/2012.December.6.2

Brysch-Herzberg, M., and Seidel, M. (2015). Yeast diversity on grapes in two German wine growing regions. Int. J. Food Microbiol. 214, 137-144. doi: 10.1016/j.ijfoodmicro.2015.07.034

Cabral, A., Rego, C., Nascimento, T., Oliveira, H., Groenewald, J. Z., and Crous, P. W. (2012). Multi-gene analysis and morphology reveal novel Ilyonectria species associated with black foot disease of grapevines. Fungal Biol-Uk 116, 62-80. doi: 10.1016/j.funbio.2011.09.010

Callahan, B. J., McMurdie, P. J., Rosen, M. J., Han, A. W., Johnson, A. J. A., and Holmes, S. P. (2016). DADA2: High-resolution sample inference from Illumina amplicon data. Nat. Methods 13, 581-58+. doi: 10.1038/ nmeth.3869

Caporaso, J. G., Kuczynski, J., Stombaugh, J., Bittinger, K., Bushman, F. D., Costello, E. K., et al. (2010). QIIME allows analysis of high-throughput community sequencing data. Nat. Methods 7, 335-336. doi: 10.1038/nmeth.f.303

Compant, S., Clement, C., and Sessitsch, A. (2010). Plant growth-promoting bacteria in the rhizo- and endosphere of plants: their role, colonization, mechanisms involved and prospects for utilization. Soil Biol. Biochem. 42, 669-678. doi: 10.1016/j.soilbio.2009.11.024

Compant, S., Mitter, B., Colli-Mull, J. G., Gangl, H., and Sessitsch, A. (2011). Endophytes of grapevine flowers, berries, and seeds: identification of cultivable bacteria, comparison with other plant parts, and visualization of niches of colonization. Microb. Ecol. 62, 188-197. doi: 10.1007/s00248-011-9883-y

Compant, S., Reiter, B., Sessitsch, A., Nowak, J., Clement, C., and Barka, E. A. (2005). Endophytic colonization of Vitis vinifera L. by plant growth promoting bacterium Burkholderia sp strain PsJN. Appl. Environ. Microb. 71, 1685-1693. doi: 10.1128/AEM.71.4.1685-1693.2005

Compant, S., Kaplan, H., Sessitsch, A., Nowak, J., Barka, E. A., and Clement, C. (2008). Endophytic colonization of Vitis vinifera L. by Burkholderia phytofirmans strain PsJN: from the rhizosphere to inflorescence tissues. Fems. Microbiol. Ecol. 63, 84-93. doi: 10.1111/j.1574-6941.2007.00410.x

Daugherty, M. P., O’neill, S., Byrne, F., and Zeilinger, A. (2015). Is vector control sufficient to limit pathogen spread in vineyards? Environ. Entomol. 44, 789797. doi: 10.1093/ee/nvv046 
Deyett, E., Roper, M. C., Ruegger, P., Yang, J., Borneman, J., and Rolshausen, P. E. (2017). Microbial landscape of the grapevine endosphere in the context of Pierce's disease. Phytobiomes 1, 138-149. doi: 10.1094/PBIOMES-08-17-0033-R

Deyett, E., Pouzoulet, J., Yang, J.-I., Ashworth, V. E., Castro, C., Roper, M. C., et al. (2019). Assessment of Pierce's disease susceptibility in Vitis vinifera cultivars with different pedigrees. Plant Pathol. 68, 1079-1087. doi: 10.1111/ppa.13027

Dissanayake, A. J., Purahong, W., Wubet, T., Hyde, K. D., Zhang, W., Xu, H. Y., et al. (2018). Direct comparison of culture-dependent and culture-independent molecular approaches reveal the diversity of fungal endophytic communities in stems of grapevine (Vitis vinifera). Fungal Divers 90, 85-107. doi: 10.1007/ s13225-018-0399-3

El-Razek, A. E., Treutter, D., Saleh, M. M. S., El-Shammaa, M., Fouad, A. A., and Abdel-Hamid, N. (2011). Effect of nitrogen and potassium fertilization on productivity and fruit quality of 'crimson seedless' grape. Agric. Biol. J. North Am. 2, 330-340. doi: 10.5251/abjna.2011.2.2.330.340

El-Tarabily, K. A. (2004). Suppression of Rhizoctonia solani diseases of sugar beet by antagonistic and plant growth-promoting yeasts. J. Appl. Microbiol. 96, 69-75. doi: 10.1046/j.1365-2672.2003.02043.x

Faist, H., Keller, A., Hentschel, U., and Deeken, R. (2016). Grapevine (Vitis vinifera) crown galls host distinct microbiota. Appl. Environ. Microb. 82, 55425552. doi: 10.1128/AEM.01131-16

Fausto, C., Mininni, A. N., Sofo, A., Crecchio, C., Scagliola, M., Dichio, B., et al. (2018). Olive orchard microbiome: characterisation of bacterial communities in soil-plant compartments and their comparison between sustainable and conventional soil management systems. Plant Ecol. Divers 11, 597-610. doi: 10.1080/17550874.2019.1596172

Gruau, C., Trotel-Aziz, P., Villaume, S., Rabenoelina, F., Clement, C., Baillieul, F., et al. (2015). Pseudomonas fluorescens PTA-CT2 triggers local and systemic immune response against Botrytis cinerea in grapevine. Mol. Plant Microbe. In. 28, 1117-1129. doi: 10.1094/MPMI-04-15-0092-R

Hahm, M. S., Sumayo, M., Hwang, Y. J., Jeon, S. A., Park, S. J., Lee, J. Y., et al. (2012). Biological control and plant growth promoting capacity of rhizobacteria on pepper under greenhouse and field conditions. J. Microbiol. 50, 380-385. doi: 10.1007/s12275-012-1477-y

Hochberg, U., Bonel, A. G., David-Schwartz, R., Degu, A., Fait, A., Cochard, H., et al. (2017). Grapevine acclimation to water deficit: the adjustment of stomatal and hydraulic conductance differs from petiole embolism vulnerability. Planta 245, 1091-1104. doi: 10.1007/s00425-017-2662-3

Karagoz, K., Ates, F., Karagoz, H., Kotan, R., and Cakmakci, R. (2012). Characterization of plant growth-promoting traits of bacteria isolated from the rhizosphere of grapevine grown in alkaline and acidic soils. Eur. J. Soil Biol. 50, 144-150. doi: 10.1016/j.ejsobi.2012.01.007

Keller, M. (2010). The science of grapevines: anatomy and physiology. Sci. Grapevines Anat. Physiol.

Khmel, I. A., Sorokina, T. A., Lemanova, N. B., Lipasova, V. A., Metlitski, O. Z., Burdeinaya, T. V., et al. (1998). Biological control of crown gall in grapevine and raspberry by two Pseudomonas spp. with a wide spectrum of antagonistic activity. Biocontrol. Sci. Technol. 8, 45-57. doi: 10.1080/09583159830423

Kim, Y. J., Lim, J., Sukweenadhi, J., Seok, J. W., Lee, S. W., Park, J. C., et al. (2019). Genomic characterization of a newly isolated rhizobacteria Sphingomonas panacis reveals plant growth promoting effect to rice. Biotechnol. Bioproc. E. 24, 119-125. doi: 10.1007/s12257-018-0386-2

Kraus, C., Voegele, R. T., and Fischer, M. (2019). Temporal development of the culturable, endophytic fungal community in healthy grapevine branches and occurrence of GTD-associated fungi. Microb. Ecol. 77, 866-876. doi: 10.1007/ s00248-018-1280-3

Krivanek, A., Riaz, S., and Walker, M. A. (2006). Identification and molecular mapping of PdR1, a primary resistance gene to Pierce's disease in Vitis. Theoretical Appl. Genet. 112, 1125-1131. doi: 10.1007/s00122-006-0214-5

Lo Piccolo, S., Ferraro, V., Alfonzo, A., Settanni, L., Ercolini, D., Burruano, S., et al. (2010). Presence of endophytic bacteria in Vitis vinifera leaves as detected by fluorescence in situ hybridization. Ann. Microbiol. 60, 161-167. doi: 10.1007/ s13213-010-0023-6

Loper, J. E., Hassan, K. A., Mavrodi, D. V., Davis, E. W., Lim, C. K., Shaffer, B. T., et al. (2012). Comparative genomics of plant-associated Pseudomonas spp.: insights into diversity and inheritance of traits Involved in multitrophic interactions. PLoS Genet. 8. e1002784. doi: 10.1371/journal.pgen.1002784
Lopez-Fernandez, S., Mazzoni, V., Pedrazzoli, F., Pertot, H., and Campisano, A. (2017). A phloem-feeding insect transfers bacterial endophytic communities between grapevine plants. Front. Microbiol. 8. doi: 10.3389/ fmicb.2017.00834

Lucas, W. J., Groover, A., Lichtenberger, R., Furuta, K., Yadav, S. R., Helariutta, Y., et al. (2013). The plant vascular system: evolution, development and functions. J. Integr. Plant Biol. 55, 294-388. doi: 10.1111/jipb.12041

Marasco, R., Rolli, E., Fusi, M., Michoud, G., and Daffonchio, D. (2018). Grapevine rootstocks shape underground bacterial microbiome and networking but not potential functionality. Microbiome 6. doi: 10.1186/s40168-017-0391-2

McMurdie, P. J., and Holmes, S. (2013). Phyloseq: an R package for reproducible interactive analysis and graphics of microbiome census data. Plos One 8, e61217. doi: 10.1371/journal.pone.0061217

Nigris, S., Baldan, E., Tondello, A., Zanella, F., Vitulo, N., Favaro, G., et al. (2018). Biocontrol traits of Bacillus licheniformis GL174, a culturable endophyte of Vitis vinifera cv. Glera. BMC Microbiol. 18, 133. doi: 10.1186/ s12866-018-1306-5

Ofek, M., Hadar, Y., and Minz, D. (2012). Ecology of root colonizing Massilia (Oxalobacteraceae). Plos One 7. doi: 10.1371/journal.pone.0040117

Perazzolli, M., Antonielli, L., Storari, M., Puopolo, G., Pancher, M., Giovannini, O., et al. (2014). Resilience of the natural phyllosphere microbiota of the grapevine to chemical and biological pesticides. Appl. Environ. Microb. 80, 3585-3596. doi: 10.1128/AEM.00415-14

Peuke, A. D. (2000). The chemical composition of xylem sap in Vitis vinifera L. cv. Riesling during vegetative growth on three different franconian vineyard soils and as influenced by nitrogen fertilizer. Am. J. Enol. Viticult. 51, 329-339.

Pieterse, C. M. J., Zamioudis, C., Berendsen, R. L., Weller, D. M., Van Wees, S. C. M., and Bakker, P. A. H. M. (2014). Induced systemic resistance by beneficial microbes. Annu. Rev. Phytopathol. 52, 347-375. doi: 10.1146/ annurev-phyto-082712-102340

Pouzoulet, J., Pivovaroff, A. L., Santiago, L. S., and Rolshausen, P. E. (2014). Can vessel dimension explain tolerance toward fungal vascular wilt diseases in woody plants? Lessons from Dutch elm disease and esca disease in grapevine. Front. Plant Sci. 5. doi: 10.3389/fpls.2014.00253

Rapicavoli, J., Ingel, B., Blanco-Ulate, B., Cantu, D., and Roper, C. (2018). Xylella fastidiosa: an examination of a re-emerging plant pathogen. Mol. Plant Pathol. 19, 786-800. doi: 10.1111/mpp.12585

Redak, R. A., Purcell, A. H., Lopes, J. R. S., Blua, M. J., Mizell, R. F., and Andersen, P. C. (2004). The biology of xylem fluid-feeding insect vectors of Xylella fastidiosa and their relation to disease epidemiology. Annu. Rev. Entomol. 49, 243-270. doi: 10.1146/annurev.ento.49.061802.123403

Savage, J. A., Clearwater, M. J., Haines, D. F., Klein, T., Mencuccini, M., Sevanto, S., et al. (2016). Allocation, stress tolerance and carbon transport in plants: how does phloem physiology affect plant ecology? Plant Cell Environ. 39, 709-725. doi: $10.1111 /$ pce. 12602

Seipke, R. F., Kaltenpoth, M., and Hutchings, M. I. (2012). Streptomyces as symbionts: an emerging and widespread theme? Fems. Microbiol. Rev. 36, 862 876. doi: 10.1111/j.1574-6976.2011.00313.x

Sicard, A., Zeilinger, A. R., Vanhove, M., Schartel, T. E., Beal, D. J., Daugherty, M. P., et al. (2018). Xylella fastidiosa: insights into an emerging plant pathogen. Annu. Rev. Phytopathol. 56 56, 181-202. doi: 10.1146/ annurev-phyto-080417-045849

Todaro, T. M., and Dami, I. E. (2017). Cane morphology and anatomy influence freezing tolerance in Vitis vinifera Cabernet Franc. Int. J. Fruit Sci. 17, 391-406. doi: 10.1080/15538362.2017.1330667

Turner, S., Pryer, K. M., Miao, V. P. W., and Palmer, J. D. (1999). Investigating deep phylogenetic relationships among cyanobacteria and plastids by small submit rRNA sequence analysis. J. Eukaryot. Microbiol. 46, 327-338. doi: 10.1111/ j.1550-7408.1999.tb04612.x

Turner, T. R., James, E. K., and Poole, P. S. (2013). The plant microbiome. Genome Biol. 14. doi: 10.1186/gb-2013-14-6-209

Varela, L. G., Smith, R. J., and Phillips, P. A., (2001). Pierce's Disease. Oakland, CA: University of California Agricultural and Natural Resources Publication 21600.

Wallis, C. M., Wallingford, A. K., and Chen, J. C. (2013). Effects of cultivar, phenology, and Xylella fastidiosa infection on grapevine xylem sap and 
tissue phenolic content. Physiol. Mol. Plant P 84, 28-35. doi: 10.1016/j. pmpp.2013.06.005

Wells, J. M., Raju, B. C., Hung, H. Y., Weisburg, W. G., Mandelcopaul, L., and Brenner, D. J. (1987). Xylella fastidiosa gen-nov, sp-nov-gram-negative, xylem-limited, fastidious plant bacteria related to Xanthomonas-spp. Int. J. Syst. Bacteriol. 37, 136-143. doi: 10.1099/00207713-37-2-136

West, E. R., Cother, E. J., Steel, C. C., and Ash, G. J. (2010). The characterization and diversity of bacterial endophytes of grapevine. Can. J. Microbiol. 56, 209216. doi: 10.1139/W10-004

Wexler, H. M. (2007). Bacteroides: the good, the bad, and the nitty-gritty. Clin. Microbiol. Rev. 20, 593-59+. doi: 10.1128/CMR.00008-07

White, T. J., Bruns, T., Lee, S., and Taylor, J., (1990). PCR - Protocols a Guide to Methods and Applications - A Laboratory Manual. Publisher: M.A. Innis, et al. (eds.), pp. 315-322. New York, Academic Press. doi: 10.1016/ B978-0-12-372180-8.50042-1
Zarraonaindia, I., Owens, S. M., Weisenhorn, P., West, K., Hampton-Marcell, J., Lax, S., et al. (2015). The soil microbiome influences grapevine-associated microbiota. Mbio 6. doi: 10.1128/mBio.02527-14

Conflict of Interest: The authors declare that the research was conducted in the absence of any commercial or financial relationships that could be construed as a potential conflict of interest.

Copyright (c) 2019 Deyett and Rolshausen. This is an open-access article distributed under the terms of the Creative Commons Attribution License (CC BY). The use, distribution or reproduction in other forums is permitted, provided the original author(s) and the copyright owner(s) are credited and that the original publication in this journal is cited, in accordance with accepted academic practice. No use, distribution or reproduction is permitted which does not comply with these terms. 